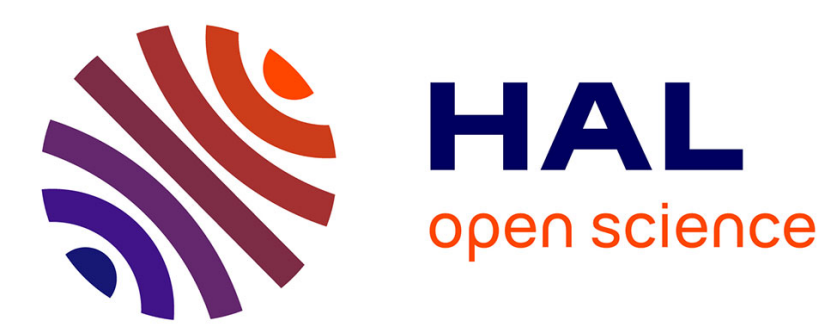

\title{
Determination of rheological properties of red blood cells by Couette viscometry
}

\author{
J. Dufaux, D. Quemada, P. Mills
}

\section{To cite this version:}

J. Dufaux, D. Quemada, P. Mills. Determination of rheological properties of red blood cells by Couette viscometry. Revue de Physique Appliquée, 1980, 15 (8), pp.1367-1374. 10.1051/rphysap:019800015080136700 . jpa-00244860

\section{HAL Id: jpa-00244860 https://hal.science/jpa-00244860}

Submitted on 1 Jan 1980

HAL is a multi-disciplinary open access archive for the deposit and dissemination of scientific research documents, whether they are published or not. The documents may come from teaching and research institutions in France or abroad, or from public or private research centers.
L'archive ouverte pluridisciplinaire HAL, est destinée au dépôt et à la diffusion de documents scientifiques de niveau recherche, publiés ou non, émanant des établissements d'enseignement et de recherche français ou étrangers, des laboratoires publics ou privés. 


\title{
Determination of rheological properties of red blood cells by Couette viscometry
}

\author{
J. Dufaux, D. Quemada and P. Mills \\ L.B.H.P., Université Paris VII, 2, place Jussieu, 75221 Paris Cedex 05, France \\ (Reçule 17 janvier 1980, révisé le 5 mai 1980, accepté le 9 mai 1980)
}

\begin{abstract}
Résumé. - L'utilisation d'un viscosimètre Couette à cylindres coaxiaux permet la mesure de la viscosité de suspensions de globules rouges dans une gamme de cisaillement variant de $0,0175 \mathrm{~s}^{-1}$ à $128 \mathrm{~s}^{-1}$. L'état d'agrégation et l'état de déformation des globules sont obtenus en adaptant les paramètres d'une relation rhéologique aux résultats expérimentaux. Différents types de suspensions de globules rouges sont étudiés. Une application aux cas pathologiques est proposée.
\end{abstract}

\begin{abstract}
The use of a Couette viscometer with coaxial cylinders enables us to measure the viscosity of red blood cell suspensions, the shear rate varying from $0.0175 \mathrm{~s}^{-1}$ to $128 \mathrm{~s}^{-1}$. Red blood cells aggregation and deformation states are obtained by fitting a rheological relation on experimental results. Different types of suspensions are studied. An application to pathological cases is proposed.
\end{abstract}

1. Introduction. - The use of low shear rate viscometers in the field of biorheology has enabled scientists to show that the viscosity of whole human blood collected on anticoagulant increases greatly when the shear rate $\dot{\gamma}$ decreases below $10 \mathrm{~s}^{-1}$. The non-newtonian characteristic of this fluid is due to several factors which play a very important part, such as : leaux),

- the deformability of the red blood cells (RBCs),

- the aggregation of RBCs (formation of rou-

- the electrical level of the RBCs membrane,

- the composition of plasma and its physicochemical state.

The study of the influence of blood viscosity on blood flow has always been main topic of interest. The importance of stasis in inflammatory reactions and of RBCs aggregation in shock due to haemorrhagics or burns has clearly been shown [1].

Unfortunately the quantitative aspect of the problem brought about in rheology for concentrated medium has until the past few years come up against the lack of satisfactory theoretical studies.

Many of the laws relating the viscosity to concentration $\eta=\eta(c)$ that we may call empiric or partially empiric have been put forward. These laws give the Einstein relation when the volumic concentration $c \rightarrow 0$, such as :

- the Brinkman-Roscoe law [2]

$\eta_{\mathrm{r}}=\frac{\eta}{\eta_{\mathrm{p}}}=(1-c)^{-2,5} \quad\left(\eta_{\mathrm{p}}=\right.$ plasma viscosity $)$
- the Mooney law [3]

$$
\eta_{\mathrm{r}}=\exp \left(\frac{2,5}{1-\lambda c}\right)
$$

where $\lambda=\frac{1}{c_{\mathrm{M}}}, c_{\mathrm{M}}$ being the packing concentration and non-newtonian laws $\tau=\eta \cdot \dot{\gamma}=\tau(\dot{\gamma})$, such as the Casson law [4]

$$
\sqrt{\tau}=A \sqrt{\dot{\gamma}}+\sqrt{\tau_{y}}
$$

where $\tau=$ shear stress,

$\tau_{y}=$ yield shear stress,

$\dot{\gamma}=$ shear rate.

It seems that these laws only allow the rheological behaviour of human blood within a limited range of concentration and shear rates.

On a basis of the optimization of viscous energy dissipation, a new theoretical approach has been developed by one of us [5].

It has led to the rheological relation :

$$
\eta_{\mathrm{r}}=\frac{\eta}{\eta_{\mathrm{p}}}=\frac{1}{\left(1-\frac{k H}{2}\right)^{2}}
$$

where

$\eta_{\mathrm{r}}=$ relative viscosity,

$\eta=$ suspension viscosity,

$\eta_{\mathrm{p}}=$ plasma viscosity,

$H=$ suspension hematocrit, 
$k=$ the effective intrinsic viscosity that can be considered as a function of maximum concentration $H_{\mathrm{m}}$ relating to the packing of RBCs that solidify the suspension :

$$
\eta_{\mathrm{r}} \rightarrow \infty, \quad k=\frac{2}{H_{\mathrm{m}}} .
$$

This law has been extended to the non-newtonian behaviour [6]. The relation (1) becomes :

$$
\begin{aligned}
& \eta_{\mathrm{r}}=\left(1-\frac{1}{2} k H\right)^{-2} \\
& k=\frac{k_{0}+k_{\infty} \dot{\gamma}_{\mathrm{r}}^{1 / 2}}{1+\dot{\gamma}_{\mathrm{r}}^{1 / 2}}, \quad \dot{\gamma}_{\mathrm{r}}=\frac{\dot{\gamma}}{\dot{\gamma}_{\mathrm{c}}} .
\end{aligned}
$$

The parameters $k_{0}$ and $k_{\infty}$ characterize the behaviour of the suspension at zero and infinite shear rate. When $\dot{\gamma}=0$ the RBCs aggregation is the predominant process. When $\dot{\gamma}$ is large, rouleaux are dispersed and single cells are deformed and oriented in the flow. The critical shear rate $\dot{\gamma}_{c}$ defines a characteristic value which separates the domain where RBCs aggregation occurs to the one where RBCs are dispersed as single cells. Within the limit $\dot{\gamma} \gg \dot{\gamma}_{c}$, the equation $\sqrt{\tau}=f(\sqrt{\dot{\gamma}})$ which is deduced from (2) is in agreement with the Casson law and allows us to find a yield shear stress [7] given by :

$$
\tau_{\mathrm{y}}^{1 / 2}=\eta_{\mathrm{p}}^{1 / 2} \dot{\gamma}_{\mathrm{c}}^{1 / 2}\left(k_{0}-k_{\infty}\right) \frac{H}{2}\left(1-\frac{k_{\infty} H}{2}\right)^{-2} .
$$

The experimental study performed in our laboratory shows the interest of these three parameters that characterize the rheological properties of different samples of blood or RBCs suspensions.

2. Methodology. - 2.1 Viscometry. - Viscosity measurements are done by the means of a Couette viscometer with coaxial cylinders (L:S. 30 Contraves, inner and outer cylinders $\varnothing=11 \mathrm{~mm}$ and $\varnothing=12 \mathrm{~mm}$ respectively, height $=20 \mathrm{~mm}$, Fig. 1). The shear

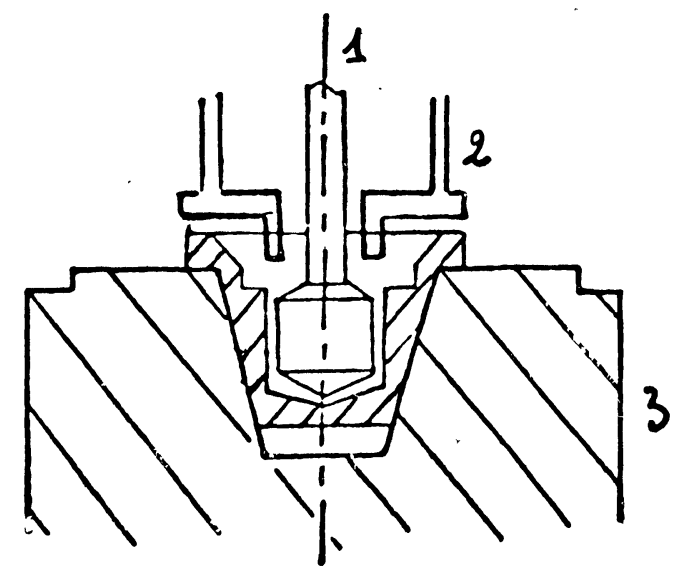

Fig. 1. - Body (1 and 2) and its guard ring 3. rate can vary from $0.0175 \mathrm{~s}^{-1}$ to $128 \mathrm{~s}^{-1}$ by 30 discrete values. The amount of liquid needed is approximatively $2 \mathrm{~cm}^{3}$. The apparatus temperature is regulated. The results that will be presented were achieved for $23^{\circ} \pm 0.1^{\circ} \mathrm{C}$. A plexiglas protection isolates the measurement cup from outer disturbances (draughts, sound vibrations...). It is difficult to get altogether rid of mechanical vibrations transmitted by the building. We obtained the most acceptable results by setting the viscometer on a tank that had been filled with $300 \mathrm{~kg}$ of sand.

The setting of the apparatus was done and the manufacturer's testing was verified with different newtonian liquids such as aceton, water, Dow chemical oils $(\eta=5 \mathrm{cP}, 50 \mathrm{cP}, 100 \mathrm{cP})$. The error of the apparatus is lower than $5 \%$ for the zones of the diagram $\eta=f(\dot{\gamma})$ which are related to the rheogram of human blood.

When we actived the first measurements with plasma and human blood $(H=0.30)$ we faced the same problems other experimenters met.

It is known that low viscosity measurements are modified by the formation of a semi solid protein film on the air blood interface. A few drops of duodecyl sodium sulfate [8] temporely suppresses these interfering effects. Unfortunately microscopic observation shows that the RBCs are deformed by this substance. Therefore, such adding has not been used. The technique of the guard ring [9] enables us to avoid this drawback. By slightly penetrating into the surface of the suspension it protects the bob from the effects due to the film (Figs. 1 and 2).

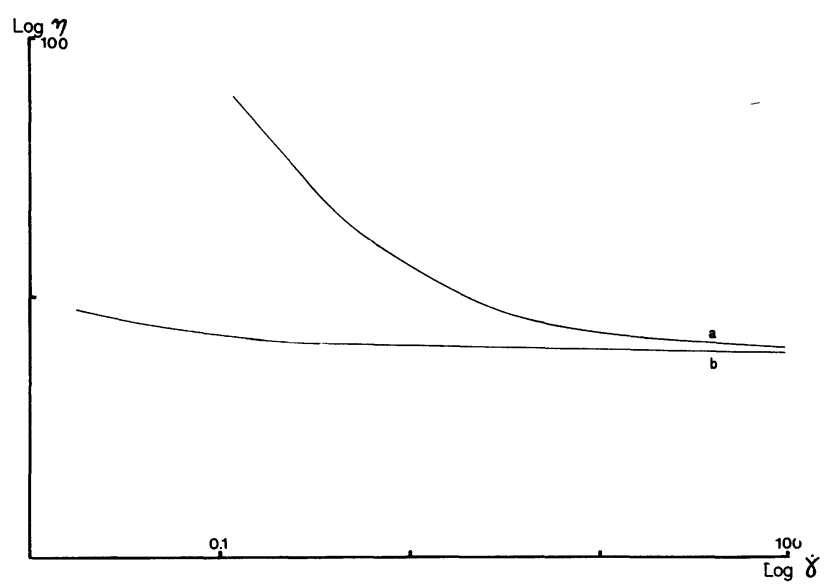

Fig. 2. - Guard ring influence. Bovine blood $H=0.26$. $\log \eta=f(\log \dot{\gamma}) . a)$ Without guard ring. $b)$ With the guard ring. The fluid is newtonian.

The human RBCs sediment quickly (sedimentation rate $=5 \mathrm{~mm} / \mathrm{h}$ at $\dot{\gamma}=0$ ). Therefore the measurements on a sample must be achieved during a limited period in order to diminish the influence of this effect. For normal samples a period less than 15 seconds for performing each measurement enables the obtention of a rheogram with no problem whatsoever [10]. 
The question whether during measurements the shear rate has to be increased or decreased has also arisen. The fact that we have chosen the decreasing variation is justified by the fact that the progressive formation of rouleaux occurs more regularly when the shear rate decreases than they dissociate when the shear increases. On one hand we begin with a homogeneous liquid in which all the dispersed blood cells are oriented along the flow lines. This structure is reproducible for different experiments and various samples. On the other hand the structure at the outset can be complex, the network of rouleaux varying from one measurement to another.

2.2 Method of DATA PRoCessing. - The gap of the measurement system being $500 \mu$, we may suppose that there is no plasma layer effects [11]. Moreover we may consider that in first approximation, shear rate is constant inside the gap. We therefore don't need to use a Krieger and Elrod's correction [12].

The number of data we must analyse is great, since they concern the following relations :

$$
\eta_{\mathrm{r}}=f(\dot{\gamma}), \quad \eta_{\mathrm{r}}=f(H), \quad \sqrt{\tau}=f(\sqrt{\dot{\gamma}}),
$$

for normal samples, pathological samples and samples to which drugs had been added.

The use of a small computer (H.P. 9821 A) allows us to overcome this processing.

A first program has been taken into account the sensitivity level of the apparatus and enable us to draw the diagram $\eta=f(\dot{\gamma}), \quad \log \eta=f(\log \dot{\gamma})$, $\tau=f(\dot{\gamma}), \sqrt{\tau}=f(\sqrt{\dot{\gamma}})$ and to record the values of $\eta, \dot{\gamma}, \tau$ for each measurement.

A second program using a least squares method leads to the parameters $k_{0}, k_{\infty}, \dot{\gamma}_{\mathrm{c}}$ by fitting the equation (2) on the resulting data $\eta=f(\dot{\gamma})$. Figure 3

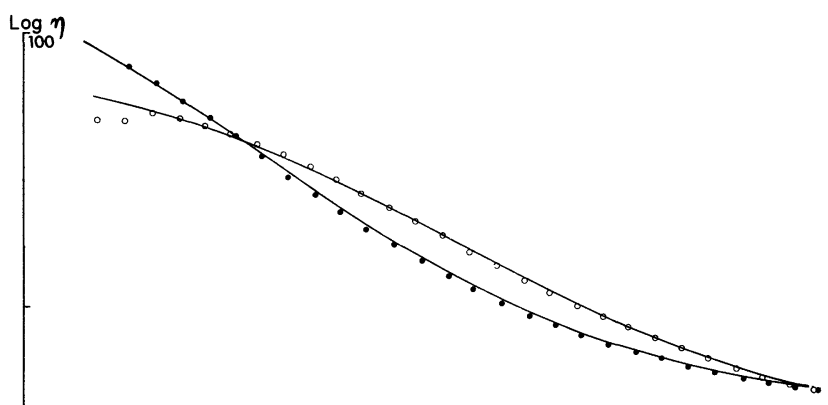

0.1

Fig. 3. - Test the law (2) : ○ Mr X, $\bullet \mathrm{Mr} \mathrm{Y}$.

$$
\begin{array}{ll}
\eta_{\mathrm{p}}=1.26 \mathrm{cP}, \quad T=37^{\circ} \mathrm{C}, & \eta_{\mathrm{p}}=1.67 \mathrm{cP}, \quad T=23^{\circ} \mathrm{C} \\
H=0.49 & H=0.46 \\
k_{0}=3.59 & k_{0}=4.16 \\
k_{\infty}=1.57 & k_{\infty}=1.61 \\
\dot{\gamma}_{\mathrm{c}}=7.93 \mathrm{~s}^{-1} & \dot{\gamma}_{\mathrm{c}}=1.76 \mathrm{~s}^{-1} .
\end{array}
$$

shows the comparison of the experimental curve $\log \eta=f(\log \dot{\gamma})$ (from which the 3 coefficients are calculated) to corresponding theoretical curve. We can notice a good agreement.

2.3 THE SUSPENSIONS. - We have prepared the suspensions (kind of anticoagulants, number of washings, speed and duration of centrifugation, duration and temperature of incubation) in accordance to literature recipes. Viscometric measurements have been performed on the following RBCs suspensions :

- RBCs in a isotonic physiological serum,

- RBCs centrifugated and resuspended in plasma (from which the white blood cells have been previously eliminated),

- RBCs hardened by glutaraldehyde,

- washed RBCs suspended in Dextran solutions of various molecular weights, at various concentrations and different ionic strengths,

- RBCs ghosts (after hemoglobin extraction by hemolysis [13]).

The hematocrit has been measured by centrifugation in microhematocrit tubes at $2000 \mathrm{~g}$ during $15 \mathrm{~min}$. This acceleration is insufficient and results in hematocrit values which have to be reduced by $5 \%$ to get the true values. It would be necessary to use a $15000 \mathrm{~g}$ centrifugation in order to eliminate that cause of error.

The data processing will be simplified and speeded up by the achievement presently underway in our laboratory of an interface between the viscometer and the computer. This interface will control the viscometer and after, will analyse the data [14].

3. Results. - 3.1 SuSPENSIONS OF BOVINE RBCs. - 3.1.1 Suspensions of RBCs in autologous plasma and in saline solution. - A first group of measurements was achieved with bovine blood and different suspensions of bovine RBCs. Although one of the characteristics of human blood, that is the formation of rouleaux no occurs in bovine blood, the importance of this measurements (Fig. 4) was to test the methodology with a less precious fluid than human blood. The absence of yield shear stress on the figure 5 can be noticed.

The results obtained with the same blood sample are shown on table I.

Table I

$\begin{array}{cccccc} & H & k_{0} & k_{\infty} & \dot{\gamma}_{\mathrm{c}} \mathrm{s}^{-1} & \left(C_{\mathrm{M}}=2 / k_{0}\right) \\ & \overline{0} & - & - & \overline{1.28} & - \\ \text { Bovine RBCs } & 0.66 & 2.59 & 2.05 & 1.28 & 0.77 \\ + \text { Physiological } & 0.58 & 2.94 & 2.23 & 1.23 & 0.68 \\ \text { serum } & 0.49 & 3.02 & 2.46 & 0.84 & 0.66 \\ T=23^{\circ} \mathrm{C}, \mathrm{pH}=7.4 & 0.41 & 3.12 & 2.70 & 0.3 & 0.64 \\ & 0.35 & 3.12 & 2.75 & 1 & 0.64 \\ \text { Bovine RBCs } & 0.65 & 2.91 & 1.78 & 5.1 & 0.69 \\ + \text { Plasma } & 0.42 & 3.02 & 1.85 & 9.6 & 0.66 \\ T=23{ }^{\circ} \mathrm{C} & 0.38 & 2.99 & 1.86 & 7.6 & 0.64 \\ & 0.35 & 3.14 & 1.95 & 170 & 0.67\end{array}$



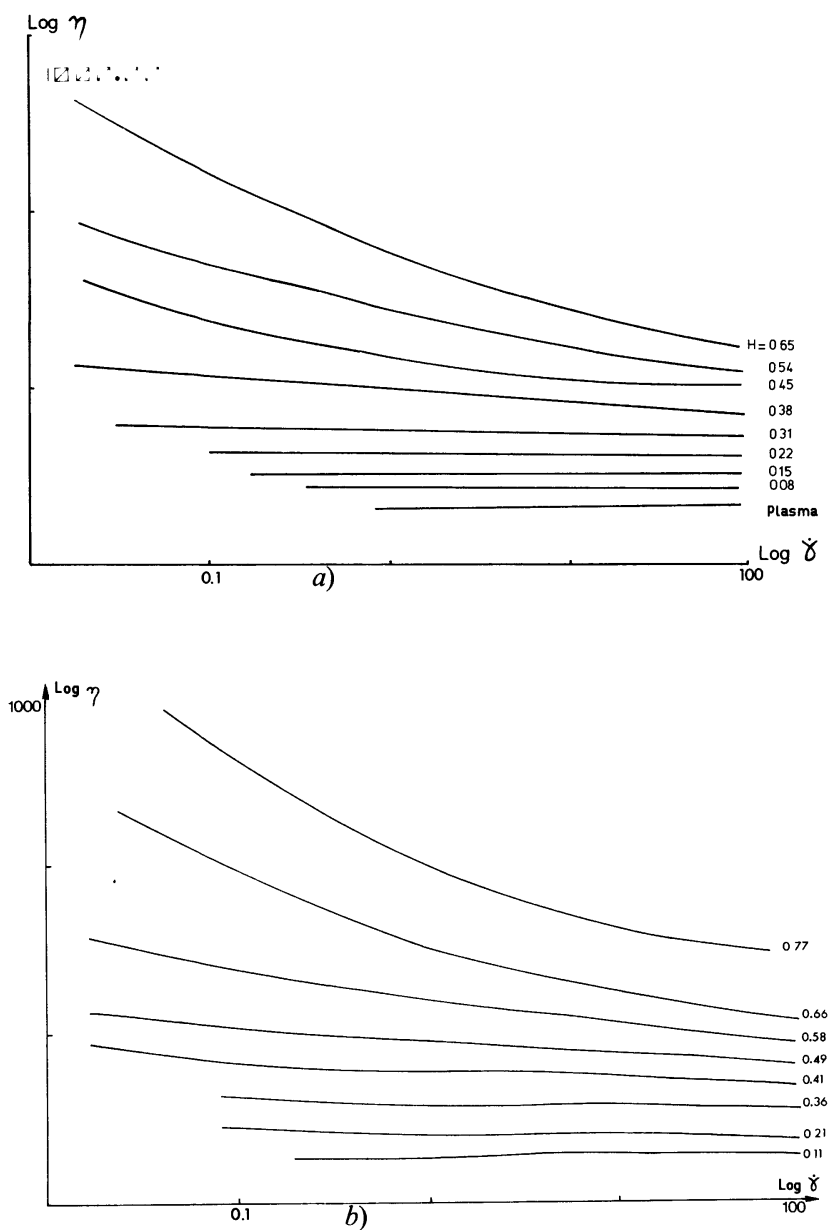

Fig. 4. - a) Rheograms of washed bovine RBCs suspended in their plasma for various hematocrits. b) Rheograms for washed bovine RBCs in saline for various hematocrits.

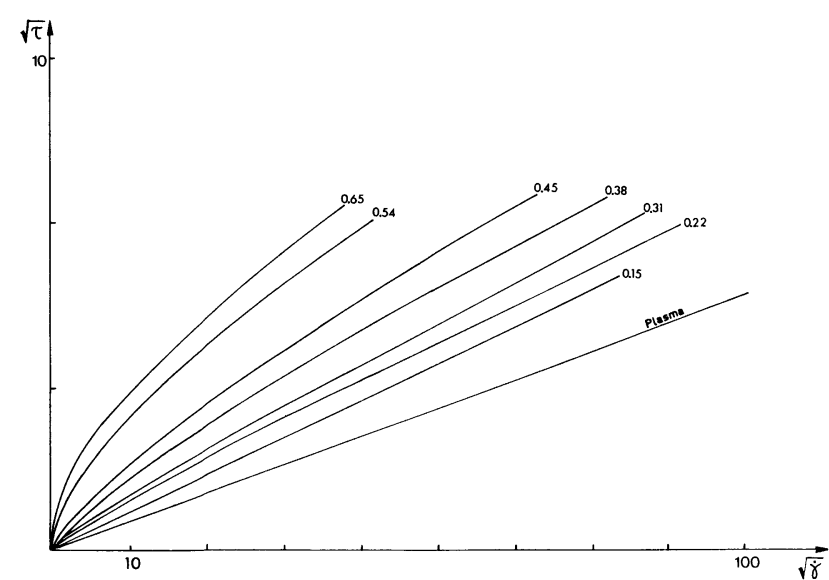

Fig. 5. - Shear stress-shear rate relation $\sqrt{\tau}=f(\sqrt{\dot{\gamma}})$. The absence of yield shear stress was noticed.

These results support the meaning of $k_{0}$ as a parameter related to the aggregating ability of the RBCs. We notice hereby, that it is almost the same value for the two suspensions in agreement with the lack of formation of rouleaux. In this case $k_{0}$ only depends on the concentration without deformation $\left(C_{\mathrm{M}}=0.61\right.$ for $H \leqslant 0.42$ ). However with highly concentrated hematocrits $k_{0}$ decreases because of the RBCs deformation by crowding phenomenon $\left(C_{\mathrm{M}}=0.69\right.$ for $H=0.66$ and even $C_{\mathrm{M}}=0.77$ for $H=0.77$ ).

The meaning of $k_{\infty}$ as a parameter of RBCs deformation and therefore of RBCs orientation is also supported by these results which offer, at same hematocrit, lower values for plasma $\left(\eta_{p}=1.2 \mathrm{cP}\right)$ than for saline solution $\left(\eta_{\mathrm{p}}=0.95 \mathrm{cP}\right)$, the deformation and orientation being higher in the former than in the latter.

Moreover the orientation effect being greater and greater as $H$ increases we obtain decreasing $k_{\infty}$ in both cases.

3.1.2 Suspensions of RBCs hardened by glutaraldehyde. - RBCs washed three times in isotonic saline have been suspended into a $2 \%$ glutaraldehyde in saline. For all shear rates at which measurements can be done, newtonian behaviour is evident (Fig. 6).

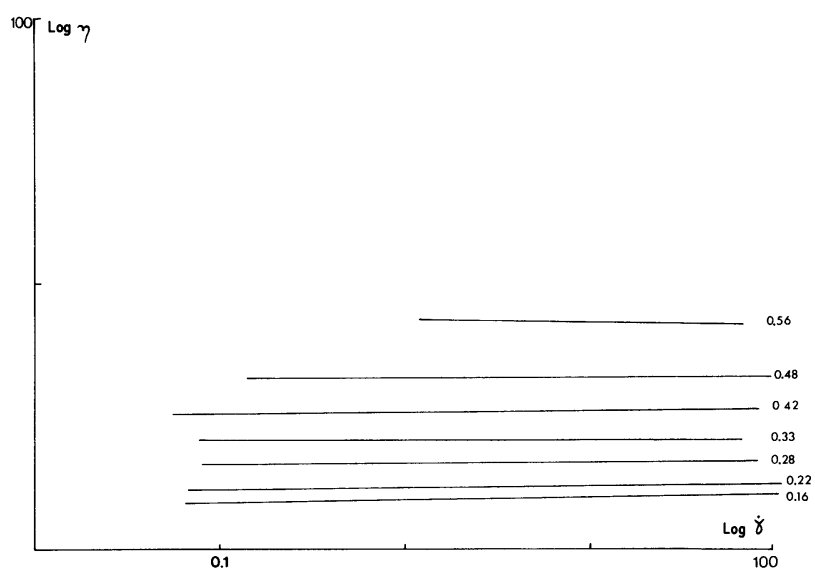

Fig. 6. - Rheograms of bovine RBCs hardened by glutaraldehyde. We can notice the absence of measurements beyond $1 \mathrm{~s}^{-1}$ for $H=0.56$. It was impossible to centre the bob.

Applying the law (1) for the variation of viscosity versus concentration gives $k$ values. Taking into account hematocrit correction by the factor 0.60 [15], the results shown in table II are obtained.

Table II.

$$
\begin{array}{lllllll}
H & 0.56 & 0.48 & 0.42 & 0.33 & 0.28 & 0.22
\end{array}
$$

$k$ after 2 days

$\begin{array}{lllllll}\text { of incubation } & 2.27 & 2.25 & 2.24 & 2.26 & 2.27 & 2.28\end{array}$

$k$ after 3 days

$\begin{array}{lllllll}\text { of incubation } & 2.85 & 2.84 & 2.79 & 2.78 & 2.82 & 2.90\end{array}$

The value of $k$ depends upon the duration of incubation of the suspension in agreement with other observation [16]. 
3.1.3 Ageing of RBCs in autologous plasma. From $50 \mathrm{~cm}^{3}$ citrated blood stored at low temperature $\left(4^{\circ} \mathrm{C}\right)$, dayly diagrams have been drawn (Fig. 7 ).

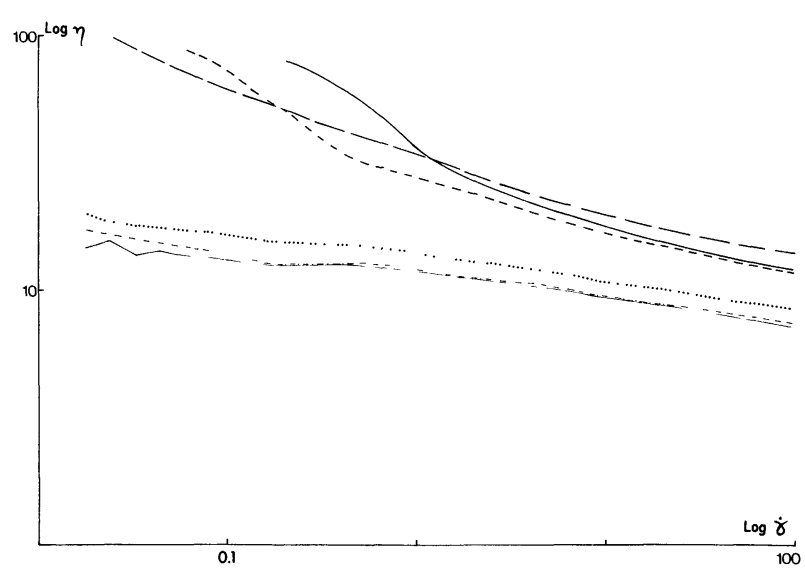

Fig. 7. - Ageing of bovine blood. After 0 h. - - - - After 24 h. 00000 After 30 h. -.-.-.- After 50 h. - After $55 \mathrm{~h}$. - - After $100 \mathrm{~h}$.

Table III.

\begin{tabular}{|c|c|c|c|c|c|c|}
\hline Time in $\mathrm{h}$ & 0 & 24 & 30 & 50 & 55 & 100 \\
\hline - & - & - & - & - & - & - \\
\hline$k_{0}$ & 3.35 & 3.43 & 3.55 & 4.66 & 4.66 & 4.89 \\
\hline$k_{\infty}$ & 2.38 & 2.51 & 2.66 & 3.02 & 3.12 & 3.40 \\
\hline$\dot{\gamma}_{\mathrm{c}} \mathbf{s}:$ & 20 & 7.4 & 7.8 & 0.7 & 1.8 & 1 \\
\hline$\eta_{\mathrm{p}} \mathrm{cP}$ & 1.6 & 1.6 & 1.6 & 1.7 & 1.7 & 2 \\
\hline
\end{tabular}

On one hand the results of table III can be interpreted for enhanced RBCs aggregability since $k_{0}$ has increased. The isolated RBCs cells have decreased in number with the time. Microscopic observation shows larger and larger flocs of RBCs. The blood tends to coagulate. On the other hand deformation of the RBCs decreases : $k_{\infty}$ increases although $\eta_{\mathrm{p}}$ does too.

3.2 Suspensions of human RBCs. - Being able to control the viscometer we undertook experimentation with human blood. We will hereby give the most relevant results.

3.2.1 RBCs in saline solution. - Table IV exhibits $k_{0}$ and $k_{\infty}$ values close the corresponding bovine ones. although slightly higher $k_{0}$. As no aggregating effects occur for human RBCs in saline, such results show the equivalence between the behaviour of these

Table IV.

$\begin{array}{cccccc} & H & k_{0} & k_{\infty} & \dot{\gamma}_{\mathrm{c}} \mathrm{s}^{-1} & \left(C_{\mathrm{M}}=2 / k_{0}\right) \\ & - & - & - & - & - \\ \text { Human RBCs } & 0.65 & 3.05 & 2.28 & 1.10 & 0.66 \\ \text { + Physiological } & 0.57 & 3.20 & 2.30 & 1.25 & 0.62 \\ \text { serum } & 0.48 & 3.28 & 2.35 & 1.50 & 0.61 \\ T=23^{\circ} \mathrm{C} & 0.30 & 3.35 & 2.35 & 1.75 & 0.60 \\ \mathrm{pH}=7.4 & 0.30 & 3.40 & 2.40 & 2.00 & 0.59\end{array}$

two dispersed particles suspensions, slight differences being related to the difference of volume of the two kinds of cells.

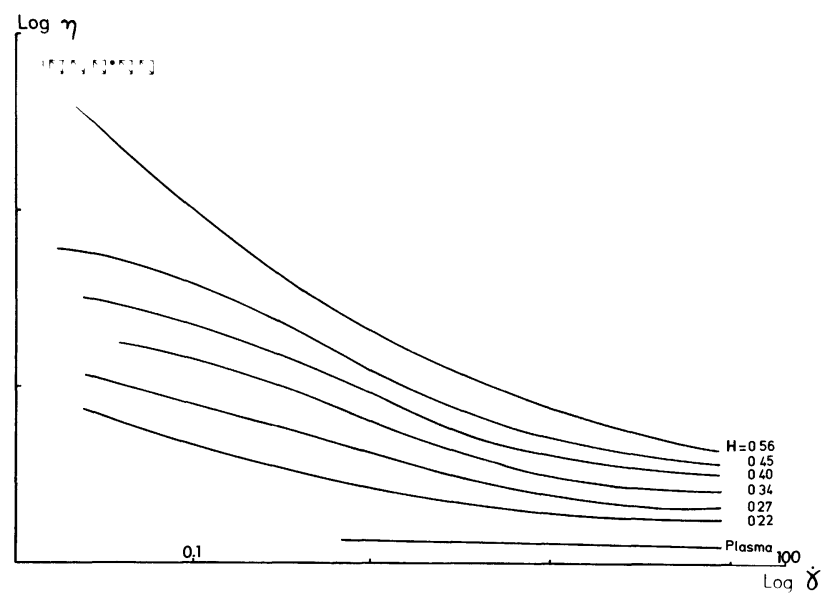

Fig. 8. - Rheograms of human RBCs suspended in their own plasma, for differents hematocrits.

3.2.2 RBCs in autologous plasma. - The results for different hematocrits are represented by the rheograms shown on diagram 8 . They will lead to the results collected on table $\mathrm{V}$. We shall interpret them in the following way.

Table V. - Human RBCs (female) with different hematocrit in their plasma. $T=23^{\circ} \mathrm{C}, \eta_{\mathrm{p}}=1.63$.

$\begin{array}{crrlc}H & k_{0} & k_{\infty} & \dot{\gamma}_{\mathrm{c}} \mathrm{s}^{-1} & \left(C_{\mathrm{M}}=2 / k_{0}\right) \\ - & - & - & \overline{-} & - \\ 0.15 & 13.35 & 2.12 & 0.038 & 0.15 \\ 0.28 & 5.79 & 2.37 & 0.367 & 0.34 \\ 0.29 & 5.52 & 2.20 & 0.55 & 0.36 \\ 0.30 & 5.56 & 2.21 & 0.39 & 0.36 \\ 0.32 & 5.27 & 2.20 & 0.55 & 0.38 \\ 0.32 & 5.29 & 2.16 & 0.58 & 0.38 \\ 0.33 & 5.11 & 2.12 & 0.73 & 0.39 \\ 0.38 & 4.45 & 2.26 & 0.92 & 0.45 \\ 0.44 & 4.03 & 1.91 & 1.49 & 0.50 \\ 0.49 & 3.73 & 1.79 & 4.59 & 0.54 \\ 0.56 & 3.38 & 1.69 & 6.38 & 0.59 \\ 0.60 & 3.17 & 1.69 & 5.97 & 0.63 \\ 0.65 & 2.98 & 1.72 & 5.91 & 0.67 \\ 0.70 & 2.77 & 1.64 & 5.53 & 0.72\end{array}$

The significance of $k_{0}$ as a relevant parameter related to the aggregation is confirmed though the values that are clearly greater when the human $\mathrm{RBCs}$ are suspended in a medium which allows the formation of rouleaux [17]. We can notice for instance that for the same hematocrit $H=0.38, k_{0}=4.95$ for RBCs in plasma and $k_{0}=3.35$ for RBCs in saline.

The different values of $k_{\infty}$ are quite similar to those obtained for bovine RBCs in their own plasma. 


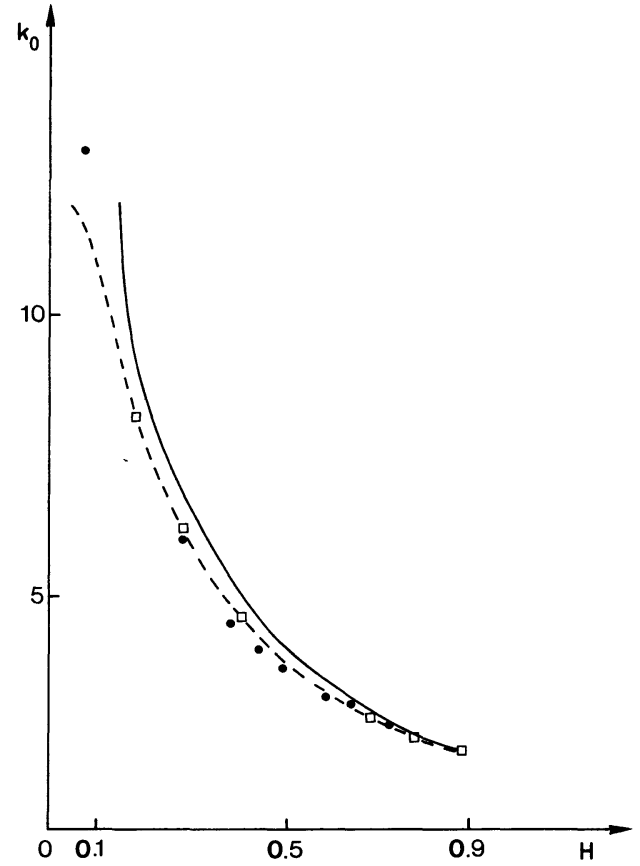

Fig، 9. - Human RBCs. Variation of $k_{0}$ versus the hematocrit. O Data of Table V. $\square$ Chien's results [14]. The full line represents the limit related to the packing concentration.

This result hints at the fact that at high $\dot{\gamma}$ the deformation of human RBCs and bovine RBCs differ only slightly since their size and form are almost identical (see Tables I and V).

The hematocrit effect when hematocrit grows up is confirmed once more.

Accepting the rheological equivalence between human and bovine individual cells, as we have just mentioned, we observe once again that $k_{0}$ characterizes the state of aggregation. For example at $H=0.38, k_{0}=4.45$ for human blood and $k_{0}=2.99$ for bovine blood.

The value of the critical shear rate varies uniformly versus hematocrit and reaches to a maximum level at $H \simeq 0.50$ (Fig. 10) which can support the idea that this parameter depends greatly upon cell-suspending fluid interaction and cell-cell interaction.

3.2.3 Ageing of human blood. - The technics used is the same as for bovine blood. Table VI sums up the main observations.

Table VI. $-H=0.41, T=23^{\circ} \mathrm{C}$.

\begin{tabular}{|c|c|c|c|c|c|}
\hline Time in $\mathrm{h}$ & 0 & 24 & 48 & 96 & 120 \\
\hline$\cdot-$ & - & - & - & - & \\
\hline$k_{0}$ & 4.13 & 4.24 & 4.21 & 4.30 & \\
\hline$k$ & 2.21 & 2.27 & 2.31 & 2.27 & \\
\hline$\dot{\gamma}_{\mathrm{c}} \mathrm{s}^{-1}$ & 0.95 & 1.05 & 1.17 & 0.93 & \\
\hline$\eta_{\mathrm{p}} \mathrm{cP}$ & 1.55 & 1.58 & 1.58 & 1.60 & \\
\hline
\end{tabular}

Microscopic observation leads to the same conclusions as for bovine blood samples. We can

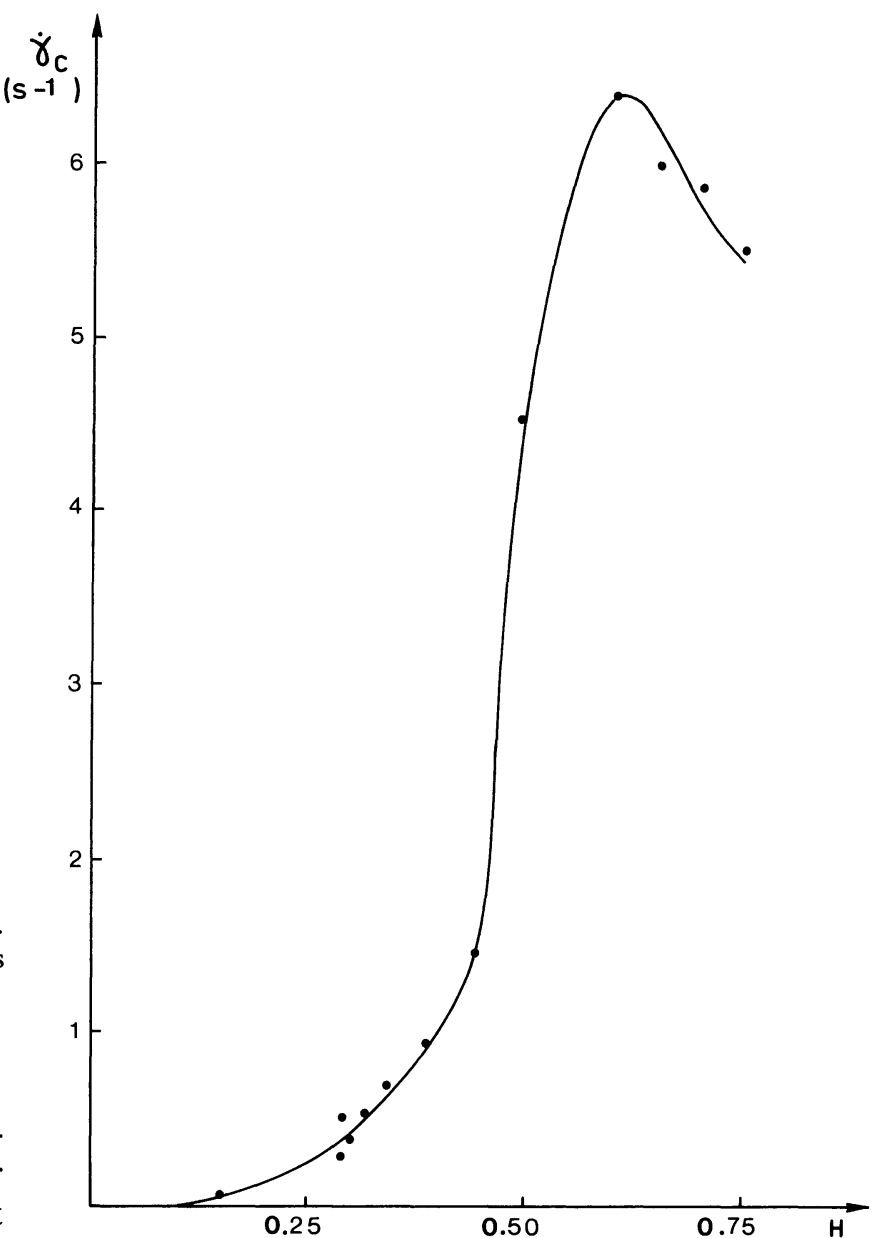

Fig. 10. - Human RBCs. Variation of the critical shear rate versus the hematocrit.

notice that human blood has identical rheological properties after 4 days contrarily to bovine blood. This difference is doubtless to the conditions of sampling for the latter which had not been controlled rigorously.

3.2.4 RBCs suspended in different Dextran solutions. - The physico-chemical properties of the plasma play an essential part in RBCs aggregation mainly by influencing the electrostatic interactions between RBCs (electroviscous effects). Such effects have been revealed for RBCs suspensions in saline $[18,19]$; the presence of fibrinogen enables the aggregation which in turn disappears in presence of albumin $[20,21]$. These observations suggest the idea of associating pathological aggregability to the lack of balance between the proteins in plasma or between macromolecules in plasma substitute (namely for the distribution of their concentrations and molecular weights). Such assertion is supported by the results obtained by replacing the plasma proteins by long molecules - the properties of which are well known such as dextrans, commonly used chemical product in medicine. Dextran molecules are electrically neutral. 
The two following series of results will confirm these observations and demonstrate once again the advantage of using the parameter $k_{0}$ to characterize the aggregating level of the suspension.

a) Human RBCs washed three times and resuspended in saline solutions of different molecular weights $M$ of Dextran (Sigma Chemical Company) have been used. Table VII gives the main results. Absence of aggregation for $M \lesssim 40000$ and its presence for $M>40000$ are found closely related to $k_{0}$ values, in agreement with microscopic observations.

A comparison of the index $A=k_{0}$ (Dextran)/ $k_{0}$ (saline) proposed by one of the authors [22] with the aggregation index :

$$
R=\frac{\left(\frac{\eta}{\eta_{\mathrm{p}}}\right) \text { dextran }}{\left(\frac{\eta}{\eta_{\mathrm{p}}}\right) \text { saline }}
$$

introduced by Brooks [23] for a specific shear rate, was satisfactory (Fig. 11a, 11b).

It may be also noticed the increasing deformation of RBCs $\left(k_{\infty}\right.$ decreasing) for $M \lesssim 40000$ when the
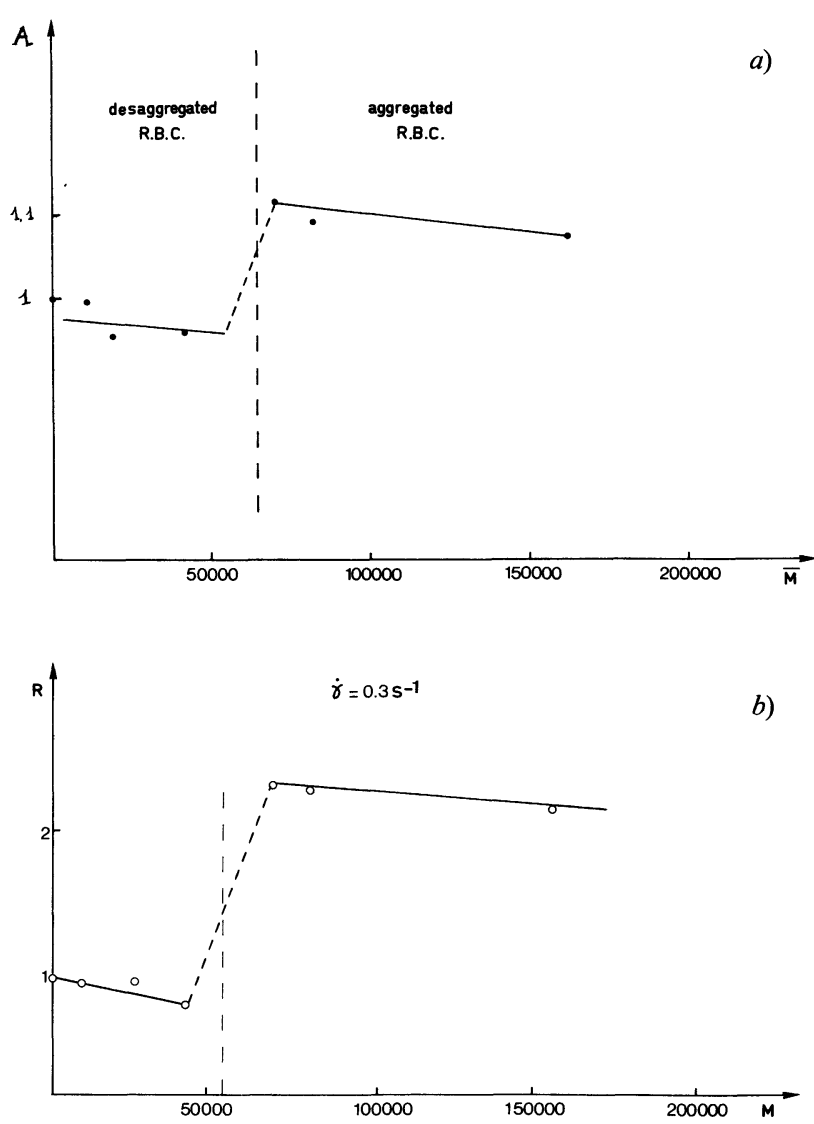

Fig. 11. - Washed human RBCs suspended in saline solution of Dextran :a) Variation of $k_{0}$ versus the molecular weight of Dextran. b) Variation of the coefficient $R$ defined by Brooks [22]. viscosity of the suspending medium raises. The jump for $k_{\infty}$ in the neighbouring of $M=40000$ is still unexplained.

Table VII.

\begin{tabular}{ccccc}
\multicolumn{1}{c}{$\begin{array}{c}\text { M } \\
-\end{array}$} & \multicolumn{1}{c}{$k_{0}$} & $k_{\infty}$ & $\dot{\gamma}_{\mathrm{c}} \mathrm{s}^{-1}$ & $\eta_{\mathrm{p}}$ \\
0 & 3.58 & 2.44 & 3.25 & 1.01 \\
10400 & 3.57 & 2.35 & 7.12 & 1.31 \\
18100 & 3.26 & 1.98 & 55.91 & 1.41 \\
41000 & 3.28 & 1.94 & 30.52 & 1.67 \\
70000 & 4.34 & 2.29 & 3.15 & 1.98 \\
80700 & 4.16 & 2.20 & 2.17 & 1.90 \\
161000 & 4.02 & 2.16 & 10.37 & 1.90 \\
$H=0.40$ & $T=23{ }^{\circ} \mathrm{C}$ & $C=3 \mathrm{~g} / 100 \mathrm{ml}$ & $\mathrm{pH}=7.4$.
\end{tabular}

$\beta$ ) RBCs washed three times and reinserted into Dextran solution $(M=80700)$ at different concentrations $C$ have been also studied. Table VIII shows a variation of $k_{0}$ versus the Dextran concentration and illustrates the fact that the aggregation increases,
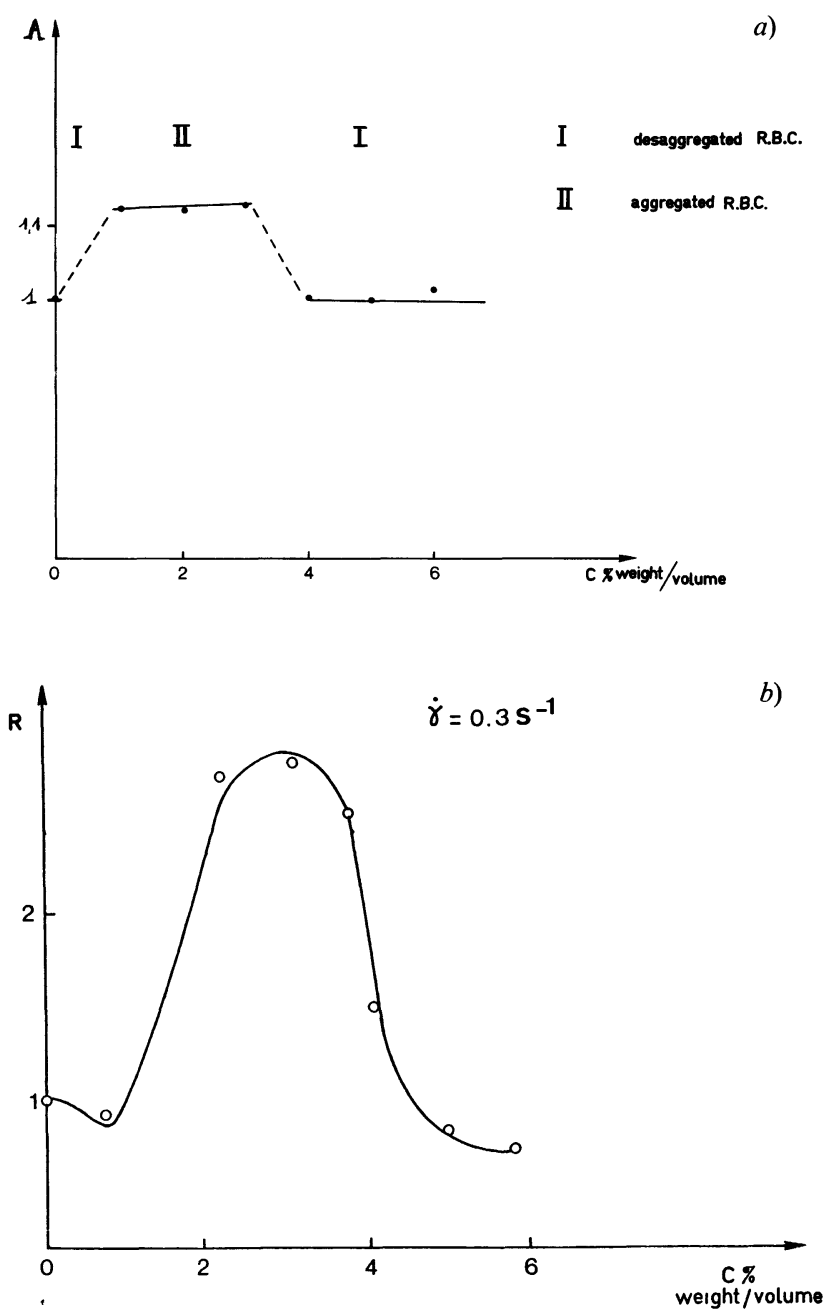

Fig. 12. - Washed human RBCs suspended in saline solution of Dextran : a) Variation of $k_{0}$ versus the Dextran concentration $(M=80700)$. b) Variation of the coefficient $R$ defined by Brooks [22]. 
as $C$ grows up to $C \simeq 3 \mathrm{~g} / 100 \mathrm{ml}$ and falls suddenly at a value close to $C=4 \mathrm{~g} / 100 \mathrm{ml}$. These observations may be compared to the Brooks'ones [23]. However this author notices an increase of aggregation up to $C=6 \mathrm{~g} / 100 \mathrm{ml}$. Perhaps a slight difference in the mean molecular weight of the Dextran that were used can explain the differences in both group of results.

Table VIII.

$\begin{array}{ccccc}\begin{array}{c}C \\ \text { \% weight/vol. }\end{array} & k_{0} & k_{\infty} & \dot{\gamma}_{\mathrm{c}} \mathrm{s}^{-1} & \eta_{\mathrm{p}} \mathrm{cP} \\ - & - & - & - & - \\ 0 & 3.58 & 2.44 & 3.25 & 1.01 \\ 1 & 4.21 & 2.29 & 2.83 & 1.24 \\ 2 & 4.20 & 2.14 & 4.01 & 1.47 \\ 3 & 4.24 & 2.12 & 2.34 & 1.90 \\ 4 & 3.55 & 2.20 & 8.30 & 2.29 \\ 5 & 3.54 & 2.26 & 7.20 & 2.45 \\ 6 & 3.72 & 2.68 & 5.68 & 2.59 \\ H=0.40 & T=23{ }^{\circ} \mathrm{C} & M=80 & 700 & \mathrm{pH}=7.4 .\end{array}$

3.2.5 Samples from smokers and patients. - The results obtained with healthy blood led us to attempt measurements for patients and people accustomed to tabacco.

A series of blind measurements done on samples of human blood taken in the same conditions from 25 different people including non smokers, light smokers ( $\$ 20$ cigarettes per day) and heavy smokers $(\geqslant 30$ cigarettes per day).

The viscometric analysis enables us to classify the 25 cases into 3 groups which reproduced the initial group distribution (two cases excepted, that they turned to be pathological cases) [24].

Another series of tests performed by Dr Lambert
(CHU Angers) on several patients suffering from diabetes and old patients suffering from vascular brain deficiency corroborate these first observations [25].

During the first study we noticed great variations of rheograms for heavy smokers [24]. Similar perturbations were observed systematically in extreme pathological cases. For the shear rate zone for which the aggregation is great $\left(\dot{\gamma} \simeq 0.1 \mathrm{~s}^{-1}\right)$, the viscosity decreases suddenly. This phenomenon is shown by a break in the rheogram. This anomaly can be interpreted by a sedimentation effect [26] which is reduced and even disappears when the patient is undergoing a medical treatment which modifies the RBCs aggregation (in the present experiment, we used acetylsalycilate of lysin) [27].

4. Conclusion. - The structure parameter $k_{0}$ and $k_{\infty}$ are in fact characteristic of the RBCs aggregation and deformation state as the results we registered have proved in different physico-chemical cases.

The analysis of this first group of results was not complete. Several topics should be analysed and more particularly related to the values of $\dot{\gamma}_{c}$.

We believe however that this first part of the study shows that the use of the parameters $k_{0}, k_{\infty}, \dot{\gamma}_{c}$ to differentiate pathological blood samples from healthy blood ones offers an interesting perspective. It is however necessary to confirm this preliminary conclusions by continuing other surveys covering a larger sample of population and also to know other characteristic values such as : the sedimentation rate, the measurement of deformation by sieves, the electrophoresis, the chemical components of plasma...

References

[1] Knisely, M. H., In W. F. Hamilton and P. Dow (Eds), Handbook of Physiology, Sect. 2 III Washington, D.C., 1965.

[2] Roscoe, R., Br. J. Appl. Phys. 3 256; Dintenfass, L., Nature 219 (1968) 956.

[3] Mooney, M., J. Colloid Sci. 6 (1945) 162.

[4] Casson, M., In Rheology of Disperse Systems, Chap. 5, C. C. Mills, eds. (Pergamon Press) 1959.

[5] Quemada, D., Rheol. Acta 16 (1977) 82.

[6] Quemada, D., Rheol. Acta 17 (1978) 632; 17 (1978) 643.

[7] Quemada. D., C.R. Hebd. Séan. Acad. Sci. 283 D (1976) 119.

[8] Matijevic, J., Pethica, B. A., Faraday Soc. Trans. 54 (1958) 1382.

[9] Joly, M., Biorheology 1 (1962) 15-20

[10] a) Copley, A. L., King, R. G., Huang, C. R., Biorheology 13 (1979) 182.

b) Mills, P., Adler, P., Dufaux, J., Quemada, D. Congrès de Pathologie vasculaire, 1978; Journal des maladies vasculaires 4197891.

[11] Barbee, J. H., Cokelet, G. R., Microvas. Res. 3 (1971) 6.

[12] Krieger, I. M., Elrod, J., Appl. Phys. 24 (1958) 2, 134.

[13] Dodge, J. T., Mitchell, C. and Hanahan, D. J., Arch. Biochem. Biophys. 100 (1968) 119.

[14] Gaudet, M., Report LBHP (to be published), 1980.

[15] Chien, S., Usami, S., Taylor, H. M., LunberG, J. L., GregerSEN, M. I., J. Appl. Phys. 21 (1966) 81.

[16] Chien, S., Usami, S., Dellenback, J., Bryant, C. A. and Gregrersev, M. I., Theor. and Clin. Hemorheology,
J. H. Hartet and A. Copley ed. (Springer Verlag, Berlin) 1971, p. 136.

[17] Quemada, D., Proceeding of the 16th International Congress of Hematology, Kyoto, Sept. 1978.

[18] Brooks, D. E., Seaman, G. V. F., Theor. Clin. Hemorheology, 1969, p. 27.

[19] Brooks, D. E., Goodwin, J. W. and Seaman, G. V. F., Biorheo$\log y 11$ (1974) 69.

[20] ChIEN, S., Science 168 (1970) 977.

[21] Merill, E. W., Margetts, W. G., Cokelet, G. R., Britten, A., Salzman, E. W., Penel, R. B. and Melin, M., in Symposium on Biorheology, A. L. Copley Ed. (Intersci. Publ. New York) 1964, p. 601.

[22] Quemada, D., IIIrd International Congress on Biorheology, La Jolla, USA, 1978.

[23] Brooks, D. E., Microcirculation. Edited by J. Grayson and W. Zingg (Plenum Press. New York and London) 1976.

[24] Dufaux, J., Quemada, D., Mills, P., Cloarec, M., Congrès de Pathologie Vasculaire, Paris, 1978.

[25] LAMBert, M., Thèse de Docteur en Médecine CHU Angers, 1978.

[26] Quemada, D., Mills, P., Dufaux, J., Lambert, M., in press, 1979, Nancy.

[27] Dufaux, J., Quemada, D., Mills, P., Lambert, M. Congrés de Pathologie Vasculaire, Paris, 1979. 